\title{
A new approach to detect small peptides clearly and sensitively by Western blotting using a vacuum-assisted detection method
}

\author{
Satoshi Tomisawa ${ }^{1}$, Chiharu Abe ${ }^{1}$, Masakatsu Kamiya ${ }^{1}$, Takashi Kikukawa ${ }^{1}$, Makoto Demura ${ }^{1}$, \\ Keiichi Kawano ${ }^{1}$ and Tomoyasu Aizawa ${ }^{1}$ \\ ${ }^{1}$ Faculty of Advanced Life Science, Hokkaido University, Sapporo 060-0810, Japan
}

Received February 21, 2013; accepted May 28, 2013

\begin{abstract}
Western blotting is a widely used technique for the detection and quantification of proteins and peptides. However, it is challenging to detect small peptides efficiently by the conventional Western blotting method with shaking, in part because the peptides readily detach from the blotted membrane. Although some modified Western blotting protocols have been developed to overcome this problem, it remains difficult to prevent peptide detachment from the membrane. In this study, we show that the previously developed vacuum-assisted detection method greatly improves the detection of small peptides without additional protocol modification. The vacuum-assisted method was developed to shorten the time required for all immunodetection steps, and all the Western blotting solutions penetrated the membrane quickly and efficiently by this method. By using this vacuum method, we succeeded in detecting small peptides that were completely undetectable by the conventional Western blotting method. We also confirmed that peptide detachment was induced even by gentle shaking in the case of the conventional method, and the detachment was accelerated when detergent was present in the buffer. Unlike in the conventional method, there is no need to shake the membrane in solution in the vacuum method. Therefore, it is thought that the small peptides could be detected sensitively only by the vacuum method.
\end{abstract}

Key words: Tricine-SDS-PAGE, PVDF membrane, vacuum method, peptide detachment

Corresponding author: Tomoyasu Aizawa, Faculty of Advanced Life Science, Hokkaido University, Sapporo 060-0810, Japan.

e-mail: aizawa@mail.sci.hokudai.ac.jp
Western blotting is a powerful procedure to identify and quantify low-abundance proteins and peptides. However, it is difficult to detect low-molecular-weight peptides efficiently, in part because they so readily detach from the blotted membranes. To avoid this detection problem, previous researchers have fixed the blotted membranes with aldehyde before applying them to the conventional Western blotting method with shaking ${ }^{1-3}$. Nishi et al. succeeded in detecting a low-molecular-weight $(6 \mathrm{kDa})$ epidermal growth factor by fixation of a gelatin-coated PVDF membrane with formaldehyde. Lee et al. reported that fixation of a blotted membrane with paraformaldehyde enables clear and strong detection of endogenous $\alpha$-synuclein $(17 \mathrm{kDa})$. Although membrane fixation by this kind of chemical crosslinkers can improve the retention of peptides on the membrane, it has also been reported that such fixation can be affect the peptide immunoreactivity due to the chemical modification ${ }^{4}$. Therefore, it is very important to develop an alternative detection method that does not alter the immunoreactivity of peptides.

In this study, we demonstrated that the previously developed vacuum-assisted detection method greatly improved the retention of small peptides without the need to fix the blotted membranes. The length of time for immunodetection could be reduced by the vacuum method, since all the Western blotting solutions permeated the membrane rapidly by this method. Because of this advantage, the vacuum method has been widely used to detect the protein of interest in many studies ${ }^{5-7}$. Two vacuum systems are commercially available for laboratory use, the SNAP i.d. system (Millipore) and the Western Q system (SciTrove). By using 
Table 1 Amino acid sequences and properties of the peptides used in this study

\begin{tabular}{|c|c|c|c|c|c|}
\hline Name & $\begin{array}{l}\text { Amino acid } \\
\text { sequence }^{\mathrm{a}}\end{array}$ & $\begin{array}{l}\text { Number of } \\
\text { cysteines }\end{array}$ & Mw & $\mathrm{pI}$ & $\begin{array}{l}\text { GRAVY } \\
\text { score }^{b}\end{array}$ \\
\hline Turtle Egg-White Protein (TEWP) & $\begin{array}{l}\text { EKKCPGRCTL } \\
\text { KCGKHERPTL } \\
\text { PYNCGKYICC } \\
\text { VPVKVK }\end{array}$ & 6 & 4080.9 & 9.4 & -0.608 \\
\hline porcine $\beta$-Defensin $2(\mathrm{pBD} 2)$ & $\begin{array}{l}\text { DHYICAKKGG } \\
\text { TCNFSPCPLF } \\
\text { NRIEGTCYSG } \\
\text { KAKCCIR }\end{array}$ & 6 & 4085.7 & 8.9 & -0.289 \\
\hline Tachyplesin I (TPI) & $\begin{array}{l}\text { KWCFRVCYRG } \\
\text { ICYRRCR }\end{array}$ & 4 & 2268.7 & 9.9 & -0.518 \\
\hline Bobinin-Like Peptide 7 (BLP7) & $\begin{array}{l}\text { GIGGALLSAG } \\
\text { KSALKGLAKG } \\
\text { LAEHFAN }\end{array}$ & 0 & 2551.9 & 9.7 & 0.415 \\
\hline Magainin 2 (MG2) & $\begin{array}{l}\text { GIGKFLHSAK } \\
\text { KFGKAFVGEI } \\
\text { MNS }\end{array}$ & 0 & 2466.9 & 10.0 & 0.083 \\
\hline Cecropin P1 (CP1) & $\begin{array}{l}\text { SWLSKTAKKL } \\
\text { ENSAKKRISE } \\
\text { GIAIAIQGGP } \\
\text { R }\end{array}$ & 0 & 3338.9 & 10.6 & -0.558 \\
\hline
\end{tabular}

${ }^{a}$ All peptides are C-terminally biotinylated.

${ }^{b}$ GRAVY stands for grand average of hydropathy. The positive GRAVY scores indicate hydrophobic peptides, and negative scores indicate hydrophilic peptides.

the vacuum method, we could detect small peptides that were not detectable by the conventional Western blotting method. In addition, we found that the multiple number of cysteine residues in peptides were related to the retention of the peptides on the membranes. The vacuum-assisted detection method was originally developed in order to shorten the time required for all immunodetection steps. To our knowledge there are no published data highlighting the detection of small peptides using the vacuum method. In this study, we assessed the effectiveness of the vacuum method for the detection of small peptides.

\section{Materials and Methods}

\section{Biotinylated antibody and peptides}

Six kinds of C-terminal biotinylated peptides (Table 1) were synthesized by Fmoc chemistry (Sigma-Aldrich Japan). A cysteine residue was introduced at the C-terminus of noncysteine containing peptides (BLP7, MG2, CP1), and then the peptides were biotinylated with iodoacetamide-biotin. In addition, cysteine-containing peptides (TEWP, pBD2, TPI), which contained a C-terminal 2-aminoethylamide moiety, were prepared using ethylenediamine trityl resin. After the fully protected peptides were cleaved from the resin, biotin was coupled to the free amino group at the C-terminus. An anti-Salmonella antibody (a kind gift from the R\&D Center, Nippon Meat Packers Inc.) was biotinylated by using a Biotin Protein Labeling Kit (Roche) according to the protocol provided by the supplier. This biotinylated polyvalent antibody was used as a positive control in the Western blotting.

\section{Electrophoresis}

Prior to loading on a gel, samples were diluted in $2 \times$ sample buffer (100 mM Tris-HCl (pH 8.4), 24\% glycerol, 1\% SDS, 2\% $\beta$-mercaptoethanol, 0.02\% Coomassie G-250) and heated at $95^{\circ} \mathrm{C}$ for $5 \mathrm{~min}$. Tricine-SDS-polyacrylamide gel electrophoresis was performed using CPAGEL (ATTO) and Compact PAGE (twin) (AE7341, ATTO) by a previously described method ${ }^{8}$.

\section{Electrotransfer}

The transfer buffers used were formulated as follows. Cathode buffer consisted of $25 \mathrm{mM}$ Tris, $40 \mathrm{mM}$ 6-amino-nhexanonic acid, and 5\% methanol; anode buffer A consisted of $300 \mathrm{mM}$ Tris and $5 \%$ methanol; anode buffer B was made up of $25 \mathrm{mM}$ Tris and $5 \%$ methanol. Prior to electrotransfer, a PVDF membrane $(6 \mathrm{~cm} \times 6 \mathrm{~cm})$ (Immobilon-Psq, pore size $0.2 \mu \mathrm{m}$; Millipore) was treated with methanol for $20 \mathrm{~s}$, transferred to a container of distilled water for $1 \mathrm{~min}$, and then soaked with the anode buffer B for $30 \mathrm{~min}$. After electrophoresis, the gels were equilibrated in anode buffer B for $5 \mathrm{~min}$. The gel and membrane were sandwiched in the following order from bottom to top: three pieces of filter paper soaked with anode buffer A, a piece of filter paper soaked with anode buffer B, the pre-wetted membrane, the gel, and three pieces of filter paper soaked with cathode buffer. Electrotransfer was performed at a constant current of $54 \mathrm{~A}$ $\left(1.5 \mathrm{~mA} / \mathrm{cm}^{2}\right)$ for $40 \mathrm{~min}$ using a HorizBLOT $2 \mathrm{M}$ blotting unit (AE6687, ATTO).

\section{Conventional shaking detection method}

The procedure of the conventional method is described in 
Tricine-SDS-polyacrylamide gel electrophoresis (50 min)

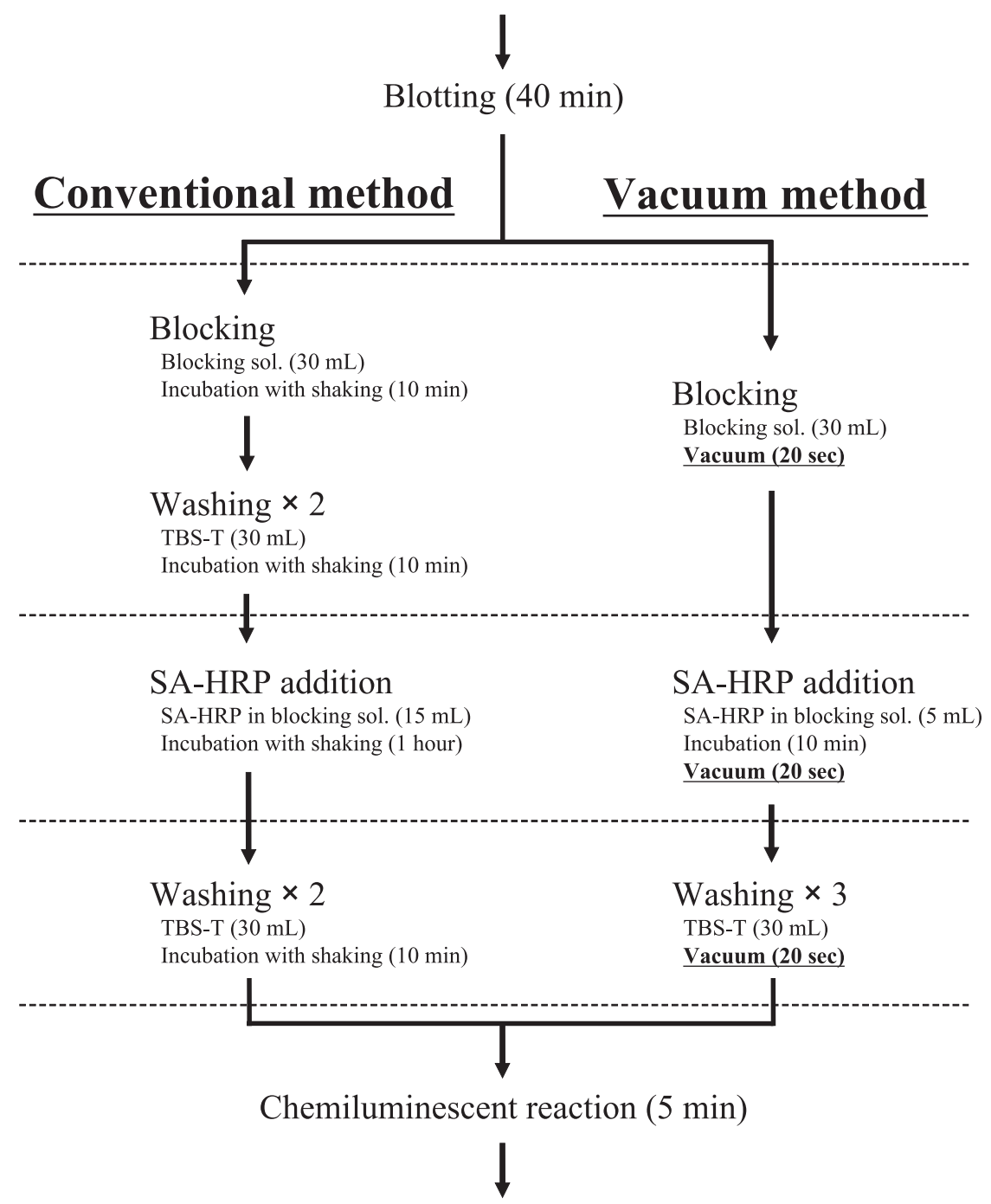

Acquisition of the luminescent signal

Figure 1 Comparison of the conventional method and the vacuum method. Flowchart of the conventional method (left) and the vacuum method (right). This figure shows solution volume and time required for each step.

Figure 1. The blotted membrane was blocked with $30 \mathrm{~mL}$ of blocking buffer (StabilGuard Choice, SurModics) for 30 min and then washed with $30 \mathrm{~mL}$ of TBS-T $(10 \mathrm{mM}$ Tris $\mathrm{HCl}$ (pH 8.0), $150 \mathrm{mM} \mathrm{NaCl}, 0.1 \%$ Tween20) twice for 10 min with gentle shaking. After washing with TBS-T, the membrane was incubated at room temperature for $1 \mathrm{~h}$ with streptavidin horseradish peroxidase (SA-HRP) conjugate (GE Healthcare) in $15 \mathrm{~mL}$ of blocking buffer; the dilution ratio was 1:1000. The membrane was then washed with $30 \mathrm{~mL}$ of TBS-T twice for $10 \mathrm{~min}$ with gentle shaking. The bound peptides and antibody were visualized by Clarity western substrate (Bio-Rad) according to the protocol provided by the supplier. The luminescent signals were acquired by using a cooled CCD camera system (AE-6971 Light Capture, ATTO).

\section{Vacuum-assisted detection method}

Detection with a SNAP i.d. vacuum system (Millipore) was performed basically according to the protocol provided by the supplier (Fig. 1). Briefly, after the blot holder containing the blotted membrane was placed in the SNAP i.d. vacuum system, $30 \mathrm{~mL}$ of blocking buffer was added and then the vacuum was turned on. After the well had emptied completely, the vacuum was turned off. Next, SA-HRP conjugate in $5 \mathrm{~mL}$ of blocking buffer (dilution ratio 1:333) was added into the blot holder. After incubation for $10 \mathrm{~min}$, the vacuum was turned on and then the membrane was washed three times with $30 \mathrm{~mL}$ of TBS-T. The chemiluminescent reaction and detection were performed using the same method as described above. 


\section{The effect of Tween 20 on peptide retention}

After electrophoresis, CP1 was electrotransferred from the gel to the pre-wetted membrane. The peptide was detected by a vacuum system as described above. The membrane was washed with TBS (10 mM Tris $\mathrm{HCl}(\mathrm{pH} 8.0), 150 \mathrm{mM}$ $\mathrm{NaCl}$ ) for $10 \mathrm{~s}$ to remove the chemiluminescent reagent. The membrane was then washed again with TBS-T or TBS for $10 \mathrm{~min}$ with gentle shaking. The residual peptides were visualized and then the luminescent signals were acquired. These procedures were repeated four times.

\section{Results and discussion}

While all six peptides were clearly detected by the vacuum method, only three peptides were weakly detected by the conventional method (Fig. 2). In contrast, the control antibody, which was a larger protein $(25 \mathrm{kDa})$ than the peptide samples $(2-4 \mathrm{kDa})$, was clearly detected at almost the same intensity by both methods (Fig. 2B). Although we used a PVDF membrane with a $0.2 \mu \mathrm{m}$ pore size, which is well-suited for detecting proteins or peptides of a molecular weight less than $20 \mathrm{kDa}$, we could not detect three peptides by the conventional method. This is probably because small peptides tend to detach from the blotted membrane more easily than the control antibody. We speculated that peptide detachment occurs during washing of the membrane in the conventional method, even if the shaking is done gently. Moreover, the membrane is also shaken gently during the blocking and incubation steps in the conventional method. These gentle shakings may induce peptide detachment from the blotted membrane. Because we used SA-HRP to detect the biotinylated protein and peptides directly, only three washing steps were needed. However, when primary and secondary antibodies are used to detect the protein and peptides, the number of washing and incubation steps increases. Accordingly, it is probable that more peptide detachment occurs when using a primary and secondary antibody. On the other hand, in the case of the vacuum-assisted detection method, there is no need for shaking during any of the immunodetection steps. We think this is the reason why we could detect small peptides sensitively by the vacuum method only.

Tween 20 is frequently used in Western blotting to reduce non-specific binding and background signals. However, a previous study showed that Tween 20 dissociates bound proteins from the nitrocellulose membrane ${ }^{9}$. To further elucidate the reasons why some peptides cannot be detected in the conventional method, we evaluated the effect of Tween 20 on peptide detachment from the blotted membrane. Because CP1 was not detected by the conventional method, we chose $\mathrm{CP} 1$ as the model peptide that easily detaches from the membrane in the conventional method. Initially, we detected $\mathrm{CP} 1$ by the vacuum method and then we subjected the membrane to repeated 10-min washings with TBS-T or TBS using gentle shaking. After the fourth washing with TBS-T, the observed intensity was decreased to $6.3 \%$ of its

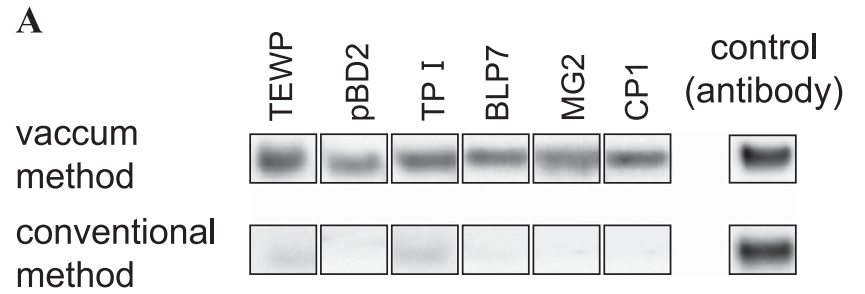

B

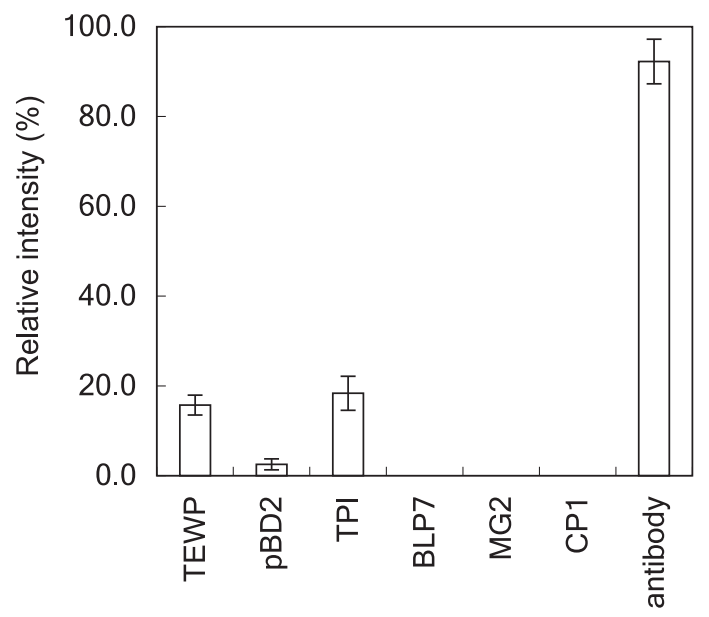

Figure 2 Effectiveness of the use of the vacuum method in Western blotting analysis of small peptides. (A) Comparison of the vacuum method (upper panel) and the conventional method (lower panel). Equimolar amounts $(0.2 \mathrm{pmol})$ of the six peptides were electrophoresed and electrotransferred. A biotinylated antibody was used as a positive control in Western blotting analysis. The luminescent signals were acquired for $120 \mathrm{~s}$ by using a cooled CCD camera system. The experiment was conducted three times. (B) The signal intensities for the conventional method were expressed in relation to those for the vacuum method.

original value (Fig. 3). Similarly, the intensity declined by $18.2 \%$ of its original value after the fourth washing with TBS. These results suggested that peptide detachment was mainly induced by washing with gentle shaking. Moreover, we clearly confirmed that detachment of the peptides from the membrane was accelerated in the presence of Tween 20. Therefore, the decrease of the peptide intensity was inevitable in the conventional method.

We could not find correlation between the retention of peptides on the membrane and the properties of the peptides (Mw, pI, GRAVY score, Table 1). Interestingly, the three cysteine-containing peptides, TEWP, pBD2, and TPI, could be detected by the conventional method, although their intensities were weak. Taking this characteristic into account, we think that the three peptides detectable by the conventional method may form intermolecular disulfide bridges. Although the tricine-SDS-polyacrylamide gel electrophoresis was performed under a reducing condition, it is possible that the cysteines in the peptides form intermolecular disul- 


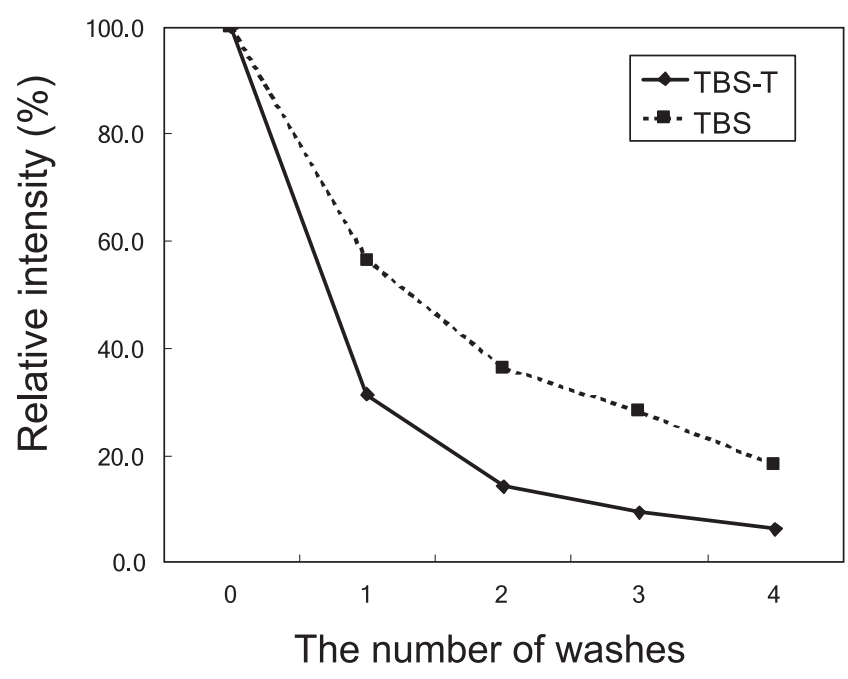

Figure 3 Effect of washing on peptide retention.Comparison of the effects of washing with TBS-T (solid line) and with TBS (dotted line). The intensity of each step was expressed in relation to the original value.

fide bridges through subsequent steps. Therefore, their retention on the membrane may be improved by intermolecular disulfide bridges. It seems likely that the formation of intermolecular disulfide bridges and the fixation with aldehyde have similar effects on the retention of peptides on the PVDF membrane.

At the present time, the fixation of blotted membranes with aldehyde is widely used to detect small proteins and peptides. However, because previous studies suggest that fixation with aldehyde affects the immunoreactivity of proteins, it is not the best way to improve peptide retention. In this study, we succeeded in detecting small peptides sensitively and clearly using the vacuum-assisted detection method without the need for fixation of the blotted membranes. The vacuum method will enable us to detect previously undetectable proteins and peptides that easily detach from the blotted membranes. In the near future, the vacuum method will be an indispensable tool for sensitive detection and accurate quantification of low-molecular-weight peptides.

\section{Acknowledgments}

This work was supported by the Programme for the Promotion of Basic and Applied Researches for Innovations in Bio-oriented Industry and a MEXT KAKENHI Grant (number 23107701).

\section{References}

1. Nishi, N., Inui, M., Miyanaka, H., Oya, H. \& Wada, F. Western Blot Analysis of Epidermal Growth Factor Using Gelatin-Coated Polyvinylidene Difluoride Membranes. Anal. Biochem. 227, 401-402 (1995).

2. Suzuki, Y., Takeda, Y. \& Ikuta, T. Immunoblotting conditions for human hemoglobin chains. Anal. Biochem. 378, 218-220 (2008).

3. Lee, B. R. \& Kamitani, T. Improved Immunodetection of Endogenous $\alpha$-Synuclein. PLoS one 6, e23939 (2011).

4. Riederer, B.M. Antigen Preservation Tests for Immunocytochemical Detection of Cytoskeletal Proteins: Influence of Aldehyde Fixatives. J. Histochem. Cytochem. 37, 675-681 (1989).

5. Fujimoto, K., Ueno, T., Nagata, N., Kashiwagi, K., Aritake, K., Amano, F. \& Urade, Y. Suppression of Adipocyte Differentiation by Aldo-keto Reductase 1B3 Acting as Prostaglandin F2 $\alpha$ Synthase. J. Biol. Chem. 285, 8880-8886 (2010).

6. Kennedy, D. J., Kuchibhotla, S., Westfall, K. M., Silverstein, R. L., Morton, R.E. \& Febbraio, M. ACD36-dependent pathway enhances macrophage and adipose tissue inflammation and impairs insulin signaling. Cardiovasc. Res. 89, 604-613 (2011).

7. Tran, T.N., Kim, S.H., Gallo, C., Amaya, M., Kyees, J. \& Narayanaswami, V. Biochemical and biophysical characterization of recombinant rat apolipoprotein E: Similarities to human apolipoprotein E3. Arch. Biochem. Biophys. 529, 18 25 (2013).

8. Schägger, H. Tricine-SDS-PAGE. Nat. Protoc. 1, 16-22 (2006).

9. Hoffman, W. L. \& Jump, A. A. Tween 20 removes antibodies and other proteins from nitrocellulose. J. Immunol. Methods. 94, 191-196 (1986). 